D)A Araştırma Notu/Research Note

Gönderim Tarihi: 07.06.2020

Kabul Tarihi: 08.06.2020

Yayımlanma Tarihi: 15.06 .2020

\title{
Tarih Metodolojisi Açısından Türkiye'deki Din Eğitimi Tarihi Çalışmaları Üzerine Bir Değerlendirme
}

\section{Recai DOĞAN*}

Tarih hem geçmişi adlandırmak için kullanılan hem de 'yaşanmış geçmişi' konu edinen ilmin adını ifade etmek için kullanılan bir kelimedir. İkinci anlamıyla tarih, "insan topluluklarının bütün faaliyetlerini, geçirdikleri gelişmeleri ve aralarında geçen olayları yer ve zaman göstererek sebep-sonuç ilişkisi içinde, belgelere dayanmak suretiyle araştıran ve günümüze nakleden sosyal ilim"dir (Özçelik 2001: 18). Sosyal bir ilim dalı olarak tarihin ilgi alanı, insan faaliyetleri sonucunda oluşan olaylardır. En genel anlamıyla görevi ise, insan düşüncesinin ifadesi olan ve zaman içinde meydana gelen olayları konu edinerek bunları şekillendiren kanunları belirlemeye, kuruluş-gelişme-çöküş koşul ve aşamalarını açıklığa kavuşturmaya çalışmaktır (Kütükoğlu 1997: 2). Geçmişine ilgi duyan ve bunun farkında olan tek varlık insandır. Dolayısıyla tarihi araştırma, insanın geçmişini öğrenmesine, bugününü anlama ve geleceğini tahmin edebilmesine büyük katkı sağlayarak onun belli bir entelektüel tecrübe, hayatını değiştirebilen bir hayal ve anlayış dinamizmi kazanmasına yardımcı olur (Bkz. Thomson 1983:1-2).

Eğitim, geçmişte insan faaliyetleri sonucu oluşan en önemli olay ve olgulardandır. İnsan, varoluşunun ilk gününden itibaren öğrenmeye ve öğretmeye çalışmış zaman içinde bu faaliyetini geliştirerek kurumsallaştırmıştır. Dolayısıyla tarihi olaylar bütünü içinde insanın eğitim ve öğretim faaliyetlerinin tari-

* Prof. Dr. Ankara Üniversitesi İlahiyat Fakültesi, Din Eğitimi Anabilim Dalı e posta: rdogan@divinity.ankara.edu.tr ORCID: 0000-0001-9668-4563

Atıf/Cite as: Doğan, R. (2020). Tarih Metodolojisi Açısından Türkiye'deki Din Eğitimi Tarihi Çalışmaları Üzerine Bir Değerlendirme. Dini Araştırmalar, 23 (57): 259-269, DOI: $10.15745 /$ da. 749041 


\section{0 • TARIHH METODOLOJISİ AÇISINDAN TÜRKIYE'DEKİ DİN EĞITTIMI TARIHİ ÇALIŞMALARI ÜZERINNE BİR DEĞERLENDİRME}

hi önemli bir yere sahiptir. Bu faaliyetlerin ana kaynaklara dayanarak bilimsel yöntemlerle neden-sonuç ilişkisi içinde ortaya konulması ise eğitimi tarihinin görevidir. Her toplum bu amaçla kendi eğitim tarihini araştırmış ve bu tarihten yararlanmaya çalışmışırır.

Günümüzde olduğu gibi geçmişte de insanı her yönüyle etkileyen unsurlardan belki de en önemlisi dindir. Din, insanın bütün tutum ve davranışlarında etkili olmuş (ve olan ve olacak) bir olgudur. İnsan hayatını bütün yönleriyle etkileyen dinin aynı zamanda eğitim ve öğretimini de yapmıştır. Bunun için yaklaşımlar, kurumlar, araç gereçler, yöntem ve teknikler vb. üretmiştir. Dolayısıyla insanlık tarihinde eğitim faaliyetleri içinde din eğitim ve öğretiminin ayrı bir yeri vardır. Bu durum, her toplumun kendi din eğitimi tarihini bilimsel olarak araştırmasına yol açmıştır.

Eğitim tarihi ve din eğitimi tarihinin bilimsel olarak araştırılması yenidir. Ancak Türkiye'de hem genel eğitim hem de din eğitimi tarihi araştırmaları Batıya nazaran daha geç zamanlarda Cumhuriyetle yapılmaya başlanmıştır. ${ }^{1}$ Bunun pek çok sebepleri vardır ve ayrı bir araştırmanın konusudur. Cumhuriyetle birlikte eğitim tarihi araştırmalarının din eğitimi tarihine nazaran daha erken dönemde başladığı söylenebilir. Ancak din eğitimi tarihi araştırmaları din-devlet, din-siyaset, din-hukuk, din-bilim gibi ilişkilerden dolayı daha geç tarihlerde yapılmaya başlanmıştır.

Cumhuriyet dönemi din eğitimi tarihini bir bütün olarak ele alıp inceleyen -belirleyebildiğimiz kadarıyla- üç çalışma öne çıkmaktadır. Din eğitimi tarihi ile ilgili bu beş eserin seçilmesinin sebebi, hepsinin isminin ortak noktasının “Türkiye'de Din Eğitimi” olmasıdır.

1. İsmet Parmaksızoğlu, Türkiye'de Din Ĕ̆itimi, Milli Eğitim Basımevi, Ankara, 1966, 88 sayfa.

2. Halis Ayhan, Türkiye'de Din Ĕgitimi, M.Ü. İlahiyat Fakültesi Vakfı Yayınları, İstanbul, 1999, 622 sayfa.

3. Mustafa Öcal, Türkiye'de Din Eğitimi, Düşünce Kitabevi Yayınları, İstanbul, 2011, 607 sayfa.

Öncelikle belirtmek gerekir ki adı geçen üç eser de çok kıymetli çalışmalardır. Cumhuriyet dönemi din eğitimi tarihi hakkında derli toplu bütüncül bilgi veren temel kaynak niteliği taşıyan çalışmalardır. Dolayısıyla günümüzde Cumhuriyet dönemi din eğitimi tarihini araştıran her araştırmacının başvurduğu araştırmalardır. Bundan sonra bu alanda temel referans kaynağı niteliğinde eser yazmak isteyen din eğitimi tarihi bilimcileri için de örneklik teşkil 
etmektedir. Bu üç eser, "yazar arkaplanı, amaç, içerik, biçim ve üslup, kaynak, tarih yazıcılığı ve anlayışı" şeklinde belirlenen çeşitli değişkenler açısından incelenmiş ardından da genel bir değerlendirme yapılmıştır.

\section{Yazar/Arkaplan}

Birinci eserin yazarı İsmet Parmaksızoğlu (1924-1984), İstanbul Üniversitesi Edebiyat Fakültesi Tarih Bölümü mezunudur. Mezuniyetinden sonra kütüphanecilik alanıyla uğraşmıştır. Daire müdürlüğüu, müsteşarlık, külttür ataşeliği ve genel müdürlük yardımcılığı ve müdürlüğü makamlarında görev yapmıştır. İki defa Din Öğretimi Genel Müdürü (1966 ve 1971) olmuştur. İsmet Parmaksızoğlu lisans eğitimini Tarih alanında yapması ve bulunduğu makamlar sebebiyle daha çok çalışmalarını tarih alanında yapmıştır. Eserlerinin büyük bir kısmı tarihi metinlerin sadeleştirilmesinden oluşur. Bunun yanı sıra kütüphaneler hakkında çeşitli yazılar neşretmiştir. Yine bazı dergilere başta tarih olmak üzere çeşitli konularda yazılar ve İslam Ansiklopedisine de çeşitli maddeler yazmıştır. Parmaksızoğlu'nun, Genel Tarih: Eski Çağlar ve Türk Tarihinin İlk Dönemleri (Yaşar Çağlayan ile birlikte, Ankara, 1976), Türklerde Devlet Anlayış1: İmparatorluk Devri 1299-1789 (Ankara, 1983), Anadolu'da ve Türklerde Hıristiyanlık: Küçük Kilise Tarihi (bakı yeri ve tarihi yok) gibi eserleri vardır. $^{2}$

İkinci eserin yazarı Halis Ayhan (1944...) Konya Yüksek İslam Enstitüsü mezunudur. Bir süre müftü, öğretmen ve yönetici olarak görev yaptıktan sonra 1970 yılında Kayseri Yüksek İslam Enstitüsünde asistan olarak akademik çalışmalara başlamıştır. Uzun yıllar Bursa Yüksek İslam Enstitüsü Müdürlüğünü daha sonra ise bir müddet İslam Ansiklopedisi Genel Müdürlüğünü yapmıştır. Ayhan özellikle din eğitim öğretimi ile din eğitimi tarihi üzerine pek çok makale ve eser yazmıştır. Halis Ayhan'ın Eğitime Giriş ve İslamiyet'in Eğitime Getirdiği Değerler (Damla Yayınları, İstanbul, 1986), Eğitim Bilimine Giriş (Şule Yayınları, İstanbul, 1995) ve Din Eğitimi ve Öğretimi (Marmara Üniversitesi İlahiyat Fakültesi Vakfı Yayınları, İstanbul, 1997) gibi eserleri vardır.

Üçüncü eserin yazarı Mustafa Öcal (1949...) Kayseri Yüksek İslam Enstitüsü mezunudur. Mezuniyetinden sonra çeşitli okullarda öğretmenlik yaptıktan sonra 1977 y1lında Bursa Yüksek İslam Enstitüsünde asistan olarak akademik camiaya girmiştir. Din Eğitimi alanında bilimsel çalışmalar yapmıştır. Alanıyla ilgili pek çok makale ve tebliğ yazan Öcal'ın İmam-Hatip Liseleri ve İlköğretim Okulları (Ensar Neşriyat, İstanbul, 1994), Eğitimde Rehberlik (Düşünce Kitabevi, İstanbul, 2004), Genç Din Eğitimcisine Mektuplar (Dü- 


\section{2 • TARİH METODOLOJISİ AÇISINDAN TÜRKIYYE'DEKİ DIN EĞİTIMİ TARIHİ ÇALIŞMALARI ÜZERINE BİR DEĞERLENDİRME}

şünce Kitabevi, İstanbul, 2005), Tanıkların Dilinden Cumhuriyet Dönemi Din Eğitimi ve Dini Hayat (I-III), (Ensar Neşriyat, İstanbul, 2008) gibi eserleri vardir.

İsmet Parmaksızoğlu, bir tarihçidir. Din eğitimi alanında sistematik bir eğitimden geçtiği ile ilgili bir bilgi yoktur. Din eğitimi ile ilgisi daha çok yaptığı Din Öğretimi Genel Müdürlüğü sebebiyle öne çıkmaktadır. Ancak aldığ1 tarih eğitimi, içinde yetiştiği kültür, olayların cereyan ettiği tarihlerde yaşaması ve Arapça ve Osmanlı Türkçesine vakıf olmasının da din eğitimi ile ilgili yaptığı çalışmasında kendisine katkı sağladığı açıktır. Zaten eserin içeriği de din alanıyla ilgili uzmanlık gerektiren bilgilerden çok din eğitiminin Cumhuriyet dönemi geçirdiği serüvenin belli değişkenlere göre tarihi gelişim açısından incelenmesidir. Dolayısıyla tarih bölümü mezunu olması bu konuda kendisine artı bir avantaj sağlamaktadır.

Halis Ayhan ve Mustafa Öcal, Yüksek İslam Enstitüsü mezunudur. Bu eğitim kurumlarının öğretim programlarında yer alan dersler incelendiğinde İslam ile ilgili fikıh, hadis tefsir gibi derslerin yanında pedagojik formasyon, psikoloji, sosyoloji, felsefe gibi derslerin de olduğu görülür. Dolayisıyla her iki yazar da hem ilahiyat hem de felsefe ve din bilimleri alanında bir öğrenim görmüştür. Parmaksızoğlu gibi doğrudan tarih eğitimi almamışlardır. Fakat özellikle aldıkları pek çok dersin tarih bilgisini içermesi sebebiyle tarihi olay ve olguları okumada belli becerilere lisans düzeyinden itibaren sahip oldukları söylenebilir.

Her üç eserin yazarı da Türkiye'de din eğitimi tarihi ile ilgili bir eser yazabilecek bilgi, beceri ve tecrübeye sahiptir.

\section{Amaç}

Bir eserin özgünlüğünü gösteren en önemli unsurlardan biri, yazarın eseri yazmakla neyi amaçladığı, ortaya koyduğu merkezi bir fikrin olup olmadığıdir.

İsmet Parmaksızoğlu kitabı yazış amacını eserin başında açıkça belirtmiyor. Ancak eserin tamamı okunduğunda yazarın amacının, modern Türkiye'de din eğitiminin memleket gerçeklerine en uygun şekilde kurulması ve rasyonel kurallara göre başarıya ulaştırmasının temellendirilmesi ve bunun niçin gerekli olduğu anlaşılıyor. Dolayısıyla yazar eserde eskisinden farklı olarak Türkiye Cumhuriyeti'nde din eğitiminin niçin ve nasıl yer alması gerektiğini temellendirme amacindadır. 
Halis Ayhan eseri yazış amacını din eğitimi tarihinin "1920-1998 yılları arasındaki macerasını açıklı̆̆ kavuşturmak" ve "din eğitimi konularının daha doğru anlaşılmasına ve daha tutarlı ve geçerli çözümler üretilmesine yardımcı olmak" (1999: XI) belirtmektedir. Ayhan özellikle genel eğitim içinde din eğitiminin niçin yer alması gerektiğini de temellendirmenin de eserin amaçlarından olduğunu vurgulamaktadır. Bu amacını; "1924'den 1998 yılına gelinceye kadar özellikle örgün din eğitimi alanında geçirmiş olduğumuz tecrübeyi, bu konular etrafındaki tartışmaları ve varılan sonuçları yazarken, günümüzdeki din eğitiminin problemlerini doğru anlamaya, genel öğretimin amaçlarının gerçekleşmesinde din eğitim ve öğretimine düşen görevleri göstermeye çalıştık." (1999: XVII) ifadeleriyle belirtir.

Mustafa Öcal eserinde yazış amacını açıkça belirtmemektedir. Eserinde Osmanlı'dan günümüze örgün ve yaygın din eğitiminin tarihi gelişimini çeşitli yönleriyle incelemeye çalışmıştır. Eserinden tamamı incelendiğinde amacın, din eğitiminin niçin gerekli olduğunun temellendirilmeye çalışıldığ 1 söylenebilir.

Adı geçen her üç eserin de en genel olarak ortak amacı, Türkiye'de din eğitimi ve öğretiminin yeni eğitim sistemi içinde niçin ve nasıl yer alması gerektiğini ilgili kaynaklardan hareketle temellendirmeye çalışmaktadır.

\section{3. İçerik}

İsmet Parmaksızoğlu'nun Türkiye'de Din Ĕ̆itimi adlı çalışması, Türkiye'de din eğitimini ele alan -belirleyebildiğimiz kadarıyla- ilk eserdir. Tek baskı yapmıştır. Eserde öncelikle Osmanlı eğitim kurumları ve eğitimi, Tanzimat öncesi (sistematik eğitimi kurumları: Sıbyan Mektebi, medrese, yaygın eğitim kurumları), Tanzimat ve Meşrutiyet devri olarak ele alınmış ve daha çok genel hatlarıla yeri geldikçe nizamnameler ve programlar açısından incelenmiştir. Cumhuriyet dönemi ise Tevhid-i Tedrisat ve Sonuçları, Din Eğitiminin Yeniden Ele Alınması ve Sonuçları, 1960'dan Sonra Dini Eğitim başlıkları altında incelenip değerlendirilmiştir. Eser, din derslerinin kaç saat yer aldığını gösteren ders cetvelleri, bazı okullarda okutulan din derslerinin müfredat programları, bazı şura kararları ile komisyonun raporlarının yer aldı ̆̆ 1 eklerle tamamlanmıştır.

Halis Ayhan'ın, Türkiye'de Din Eğitimi adlı eseri, 1920-1998 yılları arasında Türkiye'deki din eğitimini inceleyen bir çalışmadır. ${ }^{3}$ Dört bölümden oluşmaktadır. Bölümler genelde din eğitiminin örgün eğitimdeki gelişimine 


\section{4 • TARİH METODOLOJISİ AÇISINDAN TÜRKIYE'DEKİ DİN EĞITTIMI TARIHİ ÇALIŞMALARI ÜZERINE BİR DEĞERLENDİRME}

başka bir ifadeyle yer alıp almamasına ya da siyasi tarih dönemleri dikkate alınarak tarih aralıklarına göre oluşturulmuştur. Bu çerçevede birinci bölümde 1920-1933; ikinci bölümde 1933-1946; üçüncü bölümde 1946-1980; dördüncü bölümde 1980-1998 yılları arasındaki ilk ve orta okullardaki din dersleri, İmam Hatip Liseleri ve yüksek din öğretimi başlıkları altında incelenmiştir. Eserin sonunda Kur'an Kurslarındaki gelişmelere de yer verilmiştir.

Mustafa Öcal'ın, Türkiye'de Din Eğitimi adlı eseri giriş ve beş bölümden oluşmaktadır. Eser daha çok başlıklar itibariyle tematik olarak hazırlanmıştır. Bu çerçevede, giriş kısmında İslam'ın eğitim ve öğretime verdiği önem, kadınların eğitimi, ilköğretim ve medreseler hakkında bilgiler verilmiştir. Birinci bölümde Osmanlı eğitim kurumları (ilk ve orta öğretim, medreseler, meslek okulları, azınlık ve yabancı devlet okulları), ikinci bölümde İmam Hatip Liseleri (İmam ve Hatip Mektepleri Dönemi, İmam Hatip Yetiştirme Kursları Dönemi, İmam Hatip Okulları Dönemi, İmam Hatip Lisesi Dönemi, Anadolu İmam Hatip Lisesi Dönemi, 28 Şubat Süreci ve İmam Hatip Liseleri), üçüncü bölümde yüksek din öğretimi (Daru'l-Fünun ve Yüksek Din Öğretimi, Ankara Üniversitesi İlahiyat Fakültesi, Yüksek İslam Enstitüleri, Atatürk Üniversitesi İslami İlimler Fakültesi, İlahiyat Meslek Yüksek Okulları), dördüncü bölümde ilk, orta ve yükseköğretimde din öğretimi (din dersleri), beşinci bölümde ise Diyanet İşleri Başkanlığı ve yaygın din eğitimi konuları incelenmiştir.

İsmet Parmaksızoğlu eserinde özetle klasik Osmanlı, Tanzimat ve Meşrutiyet dönemlerindeki din eğitimi hakkında özet bilgi verdikten sonra özellikle Cumhuriyet dönemi genel eğitim içinde örgün din eğitiminin geçirdiği süreci ele alıp özetlemektedir. Halis Ayhan ise 1920'den 1998'e kadar örgün eğitimdeki din eğitim ve öğretimini incelemiştir. Mustafa Öcal'ın çalışması ise bu üç eser içinde en kapsamlısıdır. Eserde örgün ve yaygın din eğitiminin tarihsel gelişimi çeşitli yönleriyle Osmanlı'dan günümüze kadar incelenmektedir.

Tarih yazıcılığında diğer ilim dallarında olduğu gibi eğitim ve din eğitimi tarihi eserleri yazılırken araştırma, inceleme, öğrenme ve öğretimi kolaylaştırmak için bir sınıflandırılmasının yapılması zorunlu hale gelmiştir. Bu nedenle bölümlere ayrılan tarih zaman, yer ve konulara göre sınıflandırılarak yazılmıştır. Buna göre her üç eser de konulara göre tasnif edilmiştir. Çünkü bu eserler genel bir tarih değil alt bir konu olarak din eğitimi tarihini incelemektedir. Ancak bu tematikliğin altında da dönem, kronoloji veya tematik yaklaşım benimsenebilir. Bu bağlamda İsmet Parmaksızoğlu eserini zaman tasnifine göre yazmıştır. Osmanlı'da din eğitimini anlatırken geleneksel siyasi dönemleri Cumhuriyet'i incelerken ise belli olay veya tarihleri esas almıştır. 
Halis Ayhan eserini zaman tasnifiyle belli tarihler arasını esas alarak telif etmiştir. Aslında bu tarih aralıkları da siyasal tarihte Milli Mücadele Yılları, Atatürk Dönemi, Tek Partili Dönem, Çok Partili Dönem vb. olarak isimlendirilen tarihlerdir. $\mathrm{Bu}$ dönemlerin altında ise din eğitimi ile ilgili olay ve olguları tematik olarak incelemiştir.

Mustafa Öcal ise eserini tematik olarak yazmıştır. Ancak tematik olarak ele aldığı konuları incelerken zaman zaman belli tarihleri ve dönemleri esas almıştır.

Adı geçen her üç eserin içeriğinin yapılandırılmasında Türkiye'de din eğitimi tarihinin sınıflandırılmasında bütün tasnif türlerinin bir arada kullanıldığı söylenebilir. Aslında doğru olan da bu yaklaşımdır. Örneğin konulara göre yapılacak bir tasnifin din eğitimi tarihi araştırmalarında önemli bir yeri vardır. Ancak konuları çoğu zaman birbirinden ayırmak da mümkün olmaz ve sıkıntılar oluşur. Din eğitimi tarihini dini, sosyal, ekonomik ve siyasi tarihten ayırmak mümkün değildir. Dolayısıyla sınıflandırmalardan her biri tek başlarına kullanıldığında bütünlük bozulabilir. Onun için araştırma ve öğrenmeyi kolaylaştırma gibi pratik ve yapıcı yararı dışında bu ayırımların bir değeri olduğu söylenemez. Bir arada kullanıldıklarında bir anlam ve değer taşırlar. Din eğitiminin de pek çok olay ve olgu ile ilgili olduğu dikkate alındığında adı geçen eserlerin yapılandırılmasında farklı tasnif türlerinin kullanılması konunun derinleştirilmesine ve daha iyi anlaşılmasına katkı sağlamaktadır.

\section{Biçim ve Üslup}

Biçim ve üslup eserin iyi yazılmış olması, anlaşılmasının kolaylığı, akıcıllı̆̆ yazım kuralları gibi özellikleridir.

Her üç eser de din eğitimi tarihi alanında yazılmış bilimsel çalışmalardır. Bilimsel çalışmalarda çalışılan alanın terminolojisinin, kuramlarının vb. kullanılması önemlidir. Diğer taraftan tarih çalışıldığı için dilin dinamik yapısı dikkate alındığında belli bir dönemde kullanılan terim, cümle yapısı ve üslubun da değişmesi tabiidir. Dolayısıyla bu eserlerde kullanılan terminoloji alanın ve incelenen dönemin özelliklerinden etkilenmektedir. Özellikle Osmanlı ve Cumhuriyet'in ilk yıllarında kullanılan kelime ve terkipler her üç eser de yoğun olarak vardır. Bu durum zaten alanın bir özelliği olarak da kaçınılmazdır. Bu özelliklerine nazaran adı geçen eserler herkesin okuyup anlayabileceği bir dil ve üsluba sahiptir. Belki Halis Ayhan hocanın eserinde alanın uzmanı 


\section{6 • TARIHH METODOLOJISİ AÇISINDAN TÜRKIYE'DEKİ DIN EĞITTIMI TARIHİ ÇALIŞMALARI ÜZERINE BİR DEĞERLENDİRME}

olmayan kimseler özellikle Zabıt Ceridesi’nden veya ilk dönem dergi ve yönetmeliklerinden yapılan alıntıları anlamakta zorluk çekebilir.

Her eserde olduğu gibi bu eserlerin de paragrafların oluşumu, ardı ardına bir insicam içinde sıralanışı, imla vb. açılardan yeni basımlarında gözden geçirilmesi önemlidir.

\section{Kaynak}

Tarihin incelenip anlaşılması ve yorumlanması dokümanlar, belgeler, kalıntılar, geçmişten kalan eserler, tarihi kanıtlar ile gerçekleşmektedir. Tarihe ait bilgi veren bu malzemelere "kaynak" denir. Yazılan, söylenilen, vücuda getirilen her şey insan ve o dönem hakkında bilgi verebilir. Ancak her bilgi veren malzeme tarih için sağlıklı bir kaynak niteliğine de sahip olmayabilir. Bundan dolayı herhangi bir malzemenin tarihi kaynak olarak değer taşıması için öncelikle incelenen dönemde meydana getirilmesi ya da devrine yakın bir zamanda devrinin kaynaklarından yararlanılarak oluşturulmuş olması gerekir. Bu, tarih ilminde "ana kaynak" olarak adlandırılır. Bu tür ana kaynaklar bulunmadığı durumlarda ana kaynağ 1 gören ve ondan alıntılar yapan diğer kaynaklar kullanılır. Tarih ilminde bu tür kaynaklara "birinci elden kaynak" denir. Kaynak ile araştırma bazen karıştırılmaktadır. Bir tarih araştırmacısının, araştırmaya dayalı eserlerin hiçbir şekilde ana kaynağın yerini tutmayacağını bilmesi gerekir. Diğer taraftan kaynă̆ın müellifinin olayların geçtiği coğrafyaya yakınlı̆̆ı, görevi, sosyal statüsü, yaşı vb. kaynă̆ın değer ve güvenirliğini etkiler (Bkz. Kütükoğlu 1997: 18-28; Özçelik 2001: 83-108)

Bilindiği gibi kaynak geniş bir kavram olup tarihe ait sözlü ve yazılı dokümanları, malzemeleri içerir. Bazen belge (vesika) ile kaynak da karıştırılmaktadır. Belge tarihi kaynağın sadece yazılı kısmını ifade eder. Şiir, hikâye, menkıbe, destan, fıkra, atasözleri tarihin sözlü kaynaklarıdır. Arşiv ve arşiv malzemeleri (ferman, berat, kanunname, şer'iyye sicilleri, evkaf vb. defterler), kütüphane malzemeleri (vekayinameler, salnameler, takvimler, biyografi ve otobiyografiler, seyahatnameler, şecereler, hatıralar, tarihi romanlar, süreli yayınlar) tarihin yazılı kaynaklarıdır.

Tarih çalışmalarında özellikle yazılı kaynakların kullanımında kaynağın dış ve iç tenkidinin de yapılması önemlidir. Bu kullanılan kaynağın değeri ve güvenirliği açsından gerekli bir çalışmadır. Örneğin kullanılan bir belgenin, süreli yayının özelliklerinin bilinmesi ya da bir kişinin hatıratının ne derece güvenilir olduğunun belli kriterlere göre tenkit sürecinden geçirilmesi gerekir (Bkz. Çekmegil 1979). 
Her üç eser de yazılı tarih kaynakları kullanılarak yazılmıştır. İsmet Parmaksızoğlu, eserini yazarken kullandığı pek çok bilginin kaynağını vermez. Sadece belli yerlerde şura kararlarına veya raporlara metin içinde referans vermektedir. Eserinin sonunda yararlandığ 1 kaynakların bir bibliyografyasına toplu olarak yer vermiştir. Bibliyografya incelendiğinde genel tarih kitapları, seyahatnameler, salnameler, nizamnameler, bazı süreli yayınlar, şura kararları, komisyon raporları ve bazı araştırma eserlerinin yer aldığı dikkati çekmektedir.

Halis Ayhan eserinde kullandığı bilgiler için dipnot verir. Eserinde kaynak olarak meclis tutanakları, şura kararları, komisyon raporları, hatıratlar, biyografiler, araştırma eserleri, makaleler, ansiklopedi maddeleri ve süreli yayınlar gibi arşiv ve arşiv belgeleri ile kütüphane malzemelerini kullanmıştır. İncelediği döneme göre bazen meclis tutanaklarını bazen ise makale ve araştırma eserlerini ağırlıklı olarak referans verir.

Mustafa Öcal da kullandığı hemen her bilgi için dipnot verir. Eseri geniş bir yazılı kaynak zenginliğine sahiptir. Çalışmasında genel tarih kitapları, süreli yayınlar, araştırma eserleri, makaleler, biyografi ve otobiyografiler, sempozyumlar arşiv ve arşiv belgeleri ile kütüphane malzemelerini kullanmıştır. Herhangi bir konuyu ele alırken bu yazılı kaynakları yer yer birlikte kullanılir.

İsmet Parmaksızoğlu kaynak kullanımında daha az yazılı kaynağa baş vururken diğer iki eserde kaynak zenginliği dikkati çekmektedir. Parmaksızoğlu'nun eseri kaleme aldığı dönemde bu konuda yapılan çalışmaların az olması, kendisinin bizzat bu dönemlerde yaşaması ve olayların içinde olması onun konu ile ilgili daha temel ve doğrudan konusu ile ilgili yazılı kaynaklara yönelmesini sağlamış olabilir. Ayhan ve Öcal'ın eserlerini telif ettiklerinde ise bu konuda pek çok çalışma yayımlanmıştır. Bu onların arşiv ve arşiv malzemeleri yanında daha fazla kütüphane malzemeleri kullanmasına imkân sağlamıştır.

Bir eserde kaynakların kullanımı, o eseri yazan kişinin ele aldığı konu, tarih yazıcılığı ve anlayışı ile yakından ilgilidir. Dolayısıyla herhangi bir eserde geniş bir yazılı kaynak kullanımının olması o eserin özgün ve değerli olduğu anlamını taşımaz. Kullanılan kaynakların tarih metodolojisi kapsamında kritiğinin yapılarak kullanılması önemlidir. Adı geçen üç eserde de incelenen dönemlerin ana kaynakları kullanılmakla beraber daha çok sonraki dönemlerde yapılan araştırma eserleri, biyografi vb. kullanıldığı da dikkati çekmektedir. $\mathrm{Bu}$ elbette normaldir. Ancak ikincil el eserlerin kullanılması daha çok konu- 


\section{8 • TARIHH METODOLOJISİ AÇISINDAN TÜRKIYE'DEKİ DIN EĞITTIMI TARIHİ ÇALIŞMALARI ÜZERINNE BİR DEĞERLENDİRME}

nun çözümlemesi sürecinde ve tarih ilminin bakış açısıyla yapılır. Adı geçen eserlerde ise ana kaynak ile diğer kaynaklar yan yana kullanılmakta ve ikincil kaynaklar da ana kaynak gibi yer alabilmektedir. Dolayssıyla eserlerdeki kaynak kullanımı birbirine karısmaktadır. Eserlerdeki bu kaynak kullanımı tarzı, aslında eserin din eğitiminin tarihinden daha çok din eğitiminin niçin ve nasıl verilmesi gerektiğinin temellendirme gayretinden kaynaklanmaktadır. Ancak tarih araştırmaları ana kaynaklara dayalı olarak yapılır ve incelenen olay ve olgular sebep sonuç ilişkisi içinde analiz edilir. Temellendirme türünden bir çalışma elbette yapılabilir ve zaten de yapılmaktadır. Fakat bu tür bir bilimsel çalışmanın problematiği ve metodolojisi tarih araştırmalarından bazı yönleriyle farklılık gösterir.

\section{Tarih Yazıcılığı ve Anlayışı}

Geçmişten günümüze rivayetçi, öğretici, neden-nasılcı gibi çeşitli tarih yazıcılığı ve anlayışları vardır (Bkz. Kütükoğlu 1997: 5-9; Özçelik 2001: 3237). Aslında en genel anlamda tarih yazıcılığında iki temel yönelim vardır. Biri ideolojik diğeri ise fenomenolojik tarih yazıcılığı yaklaşımıdır. Birincisi tarihi bugünden bugünün bakışı ile okumak ikincisi ise incelenen tarihi olay ya da olguyu o günün şartları çerçevesinde okumaktır. Tarih yazıcılı̆̆ında yapılması, olması gereken ikincisidir.

İncelenen üç eser bir tarih çalışmasıdır. İçeriklerinde yer alan bilgiler, kullanılan kaynaklar bunun göstergesidir. Fakat yukarıda da belirtildiği üzere bu eserlerde din eğitiminin gerekliliği ön plana çıkmakta ve tarihi malzeme daha çok bu açıdan kullanılmaktadır. Dolayısıyla adı geçen eserler tarih araştırmaları içinde ele alınış itibariyle "çözümleyici" veya "derinliğine" tematik inceleme sınıfına dahil edilebilir. Fakat eserlerde tarihi malzemenin belli bir ön kabul çerçevesinde çözümlemesinin yapıldığı da gözükmektedir.

\section{Genel Değerlendirme}

Din eğitimi tarihi ile ilgili incelenen adı geçen üç eser Türkiye'deki bu alanla ilgili en önemli temel başvuru kaynaklarındandır. Mustafa Öcal'ın eserinde belirtiği üzere eserlerde yer alan her konunun ana kaynaklara gidilerek kapsamlı bir şekilde derinliğine araştırılması gerekir. Türkiye'de din eğitimi bilim alanı artık belli bir noktaya gelmiştir. Eskiden ulaşılamayan pek çok kaynağa artık iletişim teknolojilerinin sağladığı imkanlarla kolayca ulaşılabilmektedir. Diğer taraftan din eğitimi tarihi araştırmalarının kapsamına giren 
pek çok konu din eğitimcileri tarafından ana kaynaklara inilerek araştırılmıştir.

Bugün artık Türkiye'de din eğitimi tarihi ile ilgili tarih metodolojisinin yaklaşımıyla din eğitimi tarihinin bütün konularını kapsayacak ciltler halinde çalışılmış temel başvuru kitabını/ansiklopedisini hazırlamanın zamanı gelmiştir. Böyle bir çalışmanın elbette bir kişi tarafından yapılması mümkün olmayabilir. Ancak bilimsel bir proje olarak alan uzmanlarından oluşturulacak bir ekip tarafından bu iş gerçekleştirilebilir.

\section{Notlar}

1 Eğitim Tarihi ile ilgili yapılan ilk bağımsız araştırma; Mahmud Cevad İbnü’ş-Şeyh Nafi (1338/1922), Maârif-i Umûmiye Nezâreti, Tarihçe-i Teşkilât ve İcraât1, Matbâai Ầmire, İstanbul tarihli çalışmasıdır. Bu eser eğitim tarihini Sultan II. Mahmud'un 1824 fermanından itibaren inceler.

2 Hayatı hakkında geniş bilgi için bkz. (Şakiroğlu 2007).

3 Eser, daha sonra DEM Yayınları ve Ensar Vakfı Yayınları arasında yayımlanmışır.

\section{Kaynaklar/References}

Ayhan, H. (1999). Türkiye'de Din Eğitimi. İstanbul: M.Ü. İlahiyat Fakültesi Vakfı Yayınları.

Çekmegil, M. S. (1979). Tetkiklerde Metod ve Tenkid. Ankara: Sanih Yayınları.

Kütükoğlu, M. S. (1997). Tarih Araştırmalarında Usûl. İstanbul: Kubbealtı Neşriyatı.

Mahmud Cevad İbnü’ş-Şeyh Nafi (1338/1922). Maârif-i Umûmiye Nezâreti, Tarihçe-i Teşkilât ve İcraâtı. İstanbul: Matbâai Âmire.

Öcal, M. (2011). Türkiye'de Din Eğitimi. İstanbul: Düşünce Kitabevi Yayınları.

Özçelik, İ. (2001). Tarih Araştırmalarında Yöntem ve Teknikler. Ankara: Gündüz Eğitim ve Yayıncilik.

Parmaksızoğlu, İ. (1966). Türkiye'de Din Eğitimi. Ankara: Milli Eğitim Basımevi.

Şakiroğlu, M. H. (2007). "İsmet Parmaksızoğlu”. TDV İslam Ansiklopedisi. C.34. İstanbul.

Thomson, D. (1983). Tarihin Amacı. Çev. Salih Özbaran. İzmir: Ege Üniversitesi Edebiyat Fakültesi Yayınları. 
